\title{
Ensuring the reliability and safety of renovation facilities when introducing modern methods of building control
}

\author{
Alexey Yurgaytis ${ }^{1, *}$, Dmitry Topchy ${ }^{1}$, and Aleksandra Popova ${ }^{1, *}$ \\ ${ }^{1}$ Federal State Budget Educational Institution of Higher Education "Moscow State University of Civil \\ Engineering (National Research University)", 26, Yaroslavskoye Shosse, Moscow, Russia
}

\begin{abstract}
The purpose of this paper is to compare building control procedures in the countries of the European Union (EU) and Russia. Considered issues are related to regulatory regulation in countries, a fundamental approach to control, participants, performance results, as well as a vector for the development of construction control activities. The solution of these problems was carried out with the help of studying the foreign experience of research on this subject, as well as studying the regulatory framework for this area in the Russian Federation and the countries of the European Union. As a result of the science-metric analysis, a systematized database of official sources for regulating construction control was created. In addition, the concept of automated control was developed. The result obtained allows us to develop a comprehensive system of building control, to ensure an increase in the safety of construction and installation works. Using the data obtained, it is possible to take into account the experience of both structures and create automated software to track the construction process as a whole or as individual parts, to timely eliminate the identified defects. The possible options for improving software technologies for building control that differ from the others is by the possibility of choice of independent and dependent control parameters, by model of processing results of the construction process control in order to localize the defective situations and minimize the size of the secondary damage from the effects of the commissioning of buildings. Based on the obtained data the further development of models and algorithms for construction control of buildings and structures providing the required level of reliability and safety of their construction and operation, taking into account technical and economic efficiency criteria.
\end{abstract}

\footnotetext{
*Corresponding author: aljurgaitis@gmail.com, sasha397151948@gmail.com
} 


\section{Introduction}

In every European country, there is a construction regulation system covering building codes and building control systems. Construction control establishes minimum quality requirements for buildings to be safe, energy efficient and accessible to all who live and work in and around them. Construction control is aimed at ensuring the application and compliance with these minimum requirements. Against the background of general technical progress, increasing the volume of construction around the world, there is a complication of the procedure for approving project documentation, obtaining all necessary permits before construction, as well as controlling processes at the construction site. Respectively, it increases the flow of so-called paper work that is considered unacceptable in view of the desire for automation of the maximum number of processes. This problem can be solved by using special software that allows one to perform work more quickly, linking all the participants of building control on one site, allowing to make a quick exchange of information.

\section{Methods}

\subsection{The aim of the work}

The purpose of this work is to compare the construction control procedures in the countries of the European Union (EU) and Russia, to take into account the most qualitative control model using the advantages of the control systems of the considered countries. To achieve these goals, it is necessary to study issues related to governmental regulation in countries, a fundamental approach to control, participants, performance, as well as the vector of development of the construction industry and, in particular, building control activities. The solution of these problems was carried out with the help of studying the foreign experience of research on this subject [1-10], as well as studying the regulatory framework for this direction in the Russian Federation [11-16] . In addition, the works of Russian authors on topics that provide additional necessary information were reviewed [17-21].

\subsection{Regulation of construction activities}

The basic characteristics and various construction control systems in the EU and Russia are nearly similar. Projects must be prepared and submitted to the authority that approves their compliance with the requirements of zoning and construction standards at the stage of approval of project documentation. In addition, there is a control of compliance with project documentation and technical regulations during the execution of works on the construction site, which is supposed to be the procedure of construction control .

The applicant, builder or both are responsible for ensuring that the construction work complies with the approved project and building codes. To control construction by state or private individuals (or a combination) inspections of the construction site are carrying out.

Overview of the legal documents of the EU countries has shown that in the legal base in EU countries do not have such a wide range of documents regulating the procedure of building control in the Russian Federation (Table 1). Thus, the present study is based on a study of the literature of European authors who are engaged in comparing the order of construction control in the EU countries. 
Table 1. Basic legal documents governing the activities of construction control.

\begin{tabular}{|c|c|}
\hline Russia & European Union (EU) \\
\hline $\begin{array}{l}\text { Town Planning Code No.190- } \Phi 3 \text { dated December 29, } \\
2004\end{array}$ & \multirow{5}{*}{$\begin{array}{l}\text { e.g. BauGB (Building } \\
\text { Code, Germany) }\end{array}$} \\
\hline $\begin{array}{l}\text { Resolution No. } 468 \text { dated July } 21,2010 \text { "On the order of } \\
\text { the construction control in the implementation of } \\
\text { construction, reconstruction and overhaul of capital } \\
\text { construction" }\end{array}$ & \\
\hline $\begin{array}{l}\text { Resolution of 01.02.2006 №54 "On State Construction } \\
\text { Supervision in the Russian Federation" }\end{array}$ & \\
\hline $\begin{array}{c}\text { Federal law of 12.27.2002 № 184-FZ "On Technical } \\
\text { Regulation" }\end{array}$ & \\
\hline $\begin{array}{l}\text { Federal Law dated December 30, } 2009 \text { No. 384-Ф3 } \\
\text { "Technical Regulations on the Safety of Buildings and } \\
\text { Structures" }\end{array}$ & \\
\hline
\end{tabular}

\subsection{Participants of construction control}

Due to the similarity of the main characteristics of the building control systems of the countries in question, the roles of the persons involved in the procedure are close. Thus, it was possible to determine the functions of each participant in a generalized form for the totality of the studied systems of countries. The participants of the construction control and their functions are described in table 2.

Table 2. Participants of construction control and their functions.

\begin{tabular}{|c|c|c|}
\hline No. & $\begin{array}{c}\text { Name of the } \\
\text { participant }\end{array}$ & Description of the functions, powers of the participant \\
\hline 1 & $\begin{array}{c}\text { State Construction } \\
\text { Supervision (SCS) }\end{array}$ & $\begin{array}{c}\text { controls by authorities of the construction of capital } \\
\text { construction objects }\end{array}$ \\
\hline 2 & Building inspection & authorized to carry out inspections at the construction site \\
\hline 3 & Authorized Inspector & $\begin{array}{c}\text { is authorized to carry out private (independent) control, which } \\
\text { includes checking the project's compliance with building codes and } \\
\text { inspections at the construction site }\end{array}$ \\
\hline 4 & Designer & performs author's supervision \\
\hline 5 & Construction company & carries current control at the construction site \\
\hline 6 & Customer & monitors construction progress \\
\hline
\end{tabular}

\subsection{Principal approach to control}

In about half of the EU countries, the state is somehow involved in inspecting a construction site. Individuals (specialized organizations, designers, etc.) may be involved in building control in almost all EU countries (Table 3). 
Table 3. Participants of building control in the EU countries and Russia.

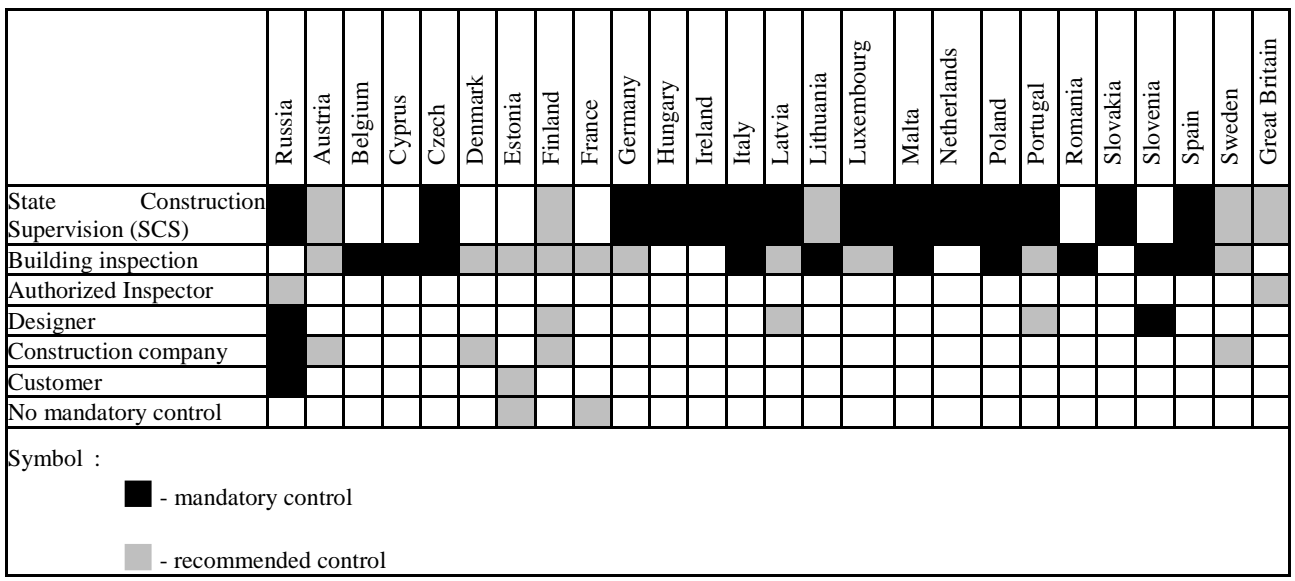

The extent to which public and private parties participate in construction controls vary considerably. The following assignments of tasks, responsibilities between public and private parties were determined:

- SCS conducts inspections at the construction site (for example, Hungary, Ireland, the Netherlands and Slovakia, Russia).

- SCS may conduct inspections at the construction site, and the Customer may appoint an authorized inspector and designer (for example, Portugal, Latvia).

- SCS is responsible for inspections at the construction site, but may designate a building inspection to monitor on its own behalf (for example, Germany).

- SCS may conduct inspections at the construction site or delegate them to the private party, for example, the customer, the construction company, the designer, or the construction inspection (for example, Finland and Sweden).

- SCS and the construction inspection (appointed by the applicant) conduct inspections at the construction site together (for example, in Bulgaria, the Czech Republic, Italy, Malta, Poland and Spain).

- The construction inspector appointed by the customer conducts inspections at the construction site, and for some categories of construction work with the participation of the SCS (for example, Lithuania).

- The construction inspector appointed by the applicant conducts inspections at the construction site (for example, Belgium, Cyprus, Romania and Slovenia)

- The construction inspector appointed by the customer conducts inspections for certain categories of construction work, and the other categories are not subject to mandatory control (for example, in Estonia and France).

- The customer can choose between conducting inspections at the construction site between the SCS and the authorized inspector (for example, England and Wales).

\subsection{Result of activities}

By the result of activity in this study refers to the official document, formed after inspections at the construction site.

Despite the similarity of characteristics of the monitoring systems of the considered countries, there are some differences in the issue of the regulations for the design of reporting documentation on the results of building site inspections. The main difference 
appears due to the fact that in the EU countries there are local standards for the inspection procedure, while in Russia the established documents are applied throughout the country. However, in both systems, the comments of one of the participants of the control during the construction of a capital construction object must be in writing. On the elimination of these deficiencies, an act is drawn up, which is signed by the person who has made comments on these shortcomings, and the person carrying out the construction. In addition, when identifying deficiencies based on the results of the inspection, the supervisory authority may require monitoring the performance of the said works and the safety of the indicated structures again after eliminating the identified deficiencies. Certificates of examination of such works, structures should be drawn up only after the elimination of identified deficiencies.

\subsection{Vector of development of construction industries}

Nowadays, the world is striving to switch to the use of the latest technologies in all areas of its activities. In the construction industry such technology is information modeling, with the selection of the model of the designed and constructed building, it has all the physical properties of an actually realized object. Despite the fact that the technology has existed since the $1970 \mathrm{~s}$, it only became actively introduced into the construction industry in the coming decade. An example of technology is the software package Autodesk. REVIT. In connection with the widespread adoption of such a design method, it is necessary to create the possibility of using the information about this building model throughout the entire life cycle of an object: from the development of an idea to operation, preservation and subsequent demolition. In our article, the construction stage is considered in more detail, therefore, at this stage it is necessary to ensure that inspections of construction control are carried out.

An automated system with the use of robotics (for example, unmanned aerial vehicles quadcopters ) will allow for continuous monitoring of the construction site and will allow to solve a number of problems associated with possible harmful and dangerous impacts at the construction site (Fig. 1).

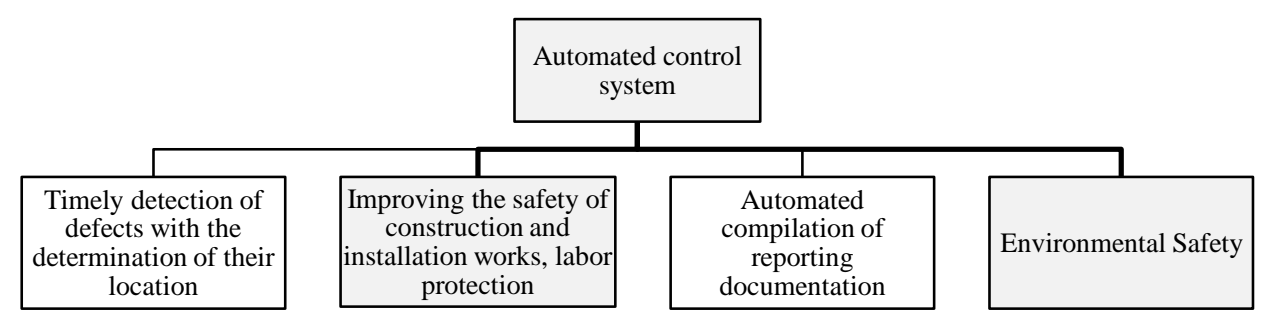

Fig. 1. Problems solved by the use of new technologies in the field of building control.

The introduction of such technology allows to facilitate the work of construction control engineers, whose duties, among other things, include ensuring compliance with safety requirements at the construction site.

In the process of studying the existing systems of automated control over the construction, the following shortcomings were identified that complicate the work and are desirable for elimination in subsequent developments:

1) Lack of functionality and to generate reports

2) Lack of integration into the building information model (BIM model) 
3) Lack of opportunity and automatic comparison of the actual result of construction activities with design documentation

4) Lack of integration into the apparatus of calibration dependencies for the implementation of indirect non-destructive methods

5) Poor positioning accuracy on the object (for identifying the location of the defect, for example)

6) The need of integration with the updated standard base subject, in which the construction is carried out

7) In order to ensure the formality of the created document in the software, duplication is necessary either on paper due to the fact that the contractor's signature is required or on a third-party carrier for signing with an electronic signature in this regard there is no desired reduction in document flow at this stage of development of such systems.

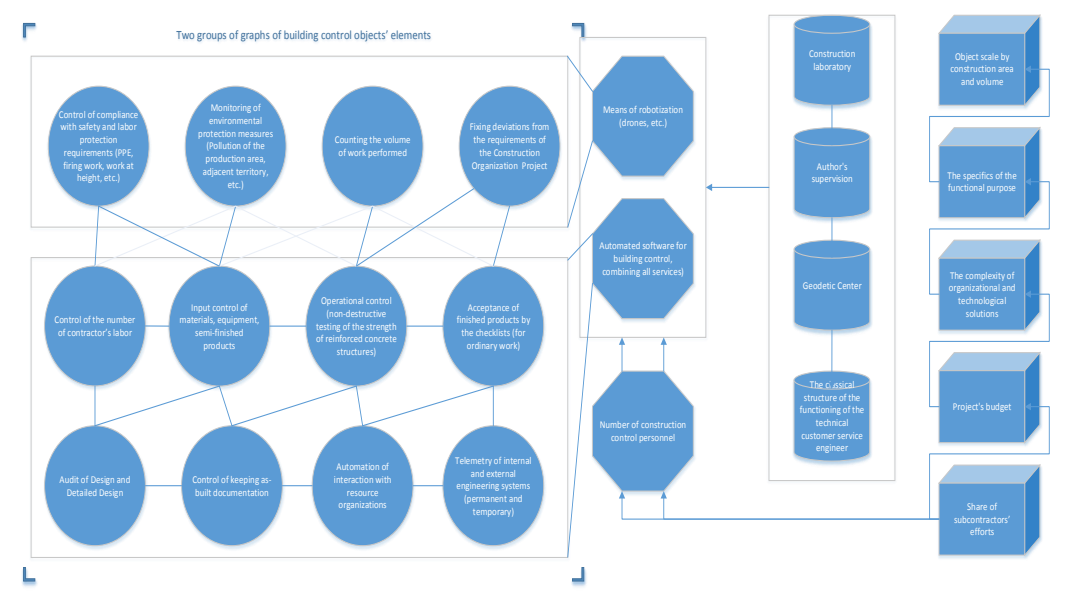

Fig. 2. The general scheme of the introduction of new technologies in the building control system.

\section{Minuses:}

1 ) at the moment, the official introduction of such software is not legitimized

2 ) the use of such software requires the connection to the system of all participants in the construction industry, which at this stage of system implementation is not possible to ensure.

\section{Results}

Thus, the widespread implementation of the system is necessary for its convenient use by all participants of the investment and construction project, ranging from ideological developers to building control during construction and operating companies, and the development of updates to improve the quality of the products provided. The software allows one to solve a set of tasks during construction control, such as: automated generation of a defect list based on the data obtained during the inspection, as well as to effectively eliminate the noted defects, display a technical report in the required form, taking into account the amount of work performed to facilitate the monthly reconciliation and submission of an act of completed work, automated scheduling. Among other things, this system will allow for monitoring control. The fact that the program is connected to the system of geopositioning and, accordingly, the user will not be able to "hold control of the construction site, without leaving his office". The analysis presented in this paper gives 
an overall picture of the construction control systems in the EU and Russia. Further harmonization and structuring of the data will provide a complete list of the provisions of the building inspection, and use the information in the software package.

\section{References}

1. J. M. Pedro, F. V. Henk, Technical building regulations in EU countries presentation: comparison of their organization and formulation (2010)

2. F. Meijer, H. Visscher, L. Sheridan, Building Regulations in Europe, Part I: A Comparison of the Systems of Building Control in Eight European Countries (Delft University Press, Delft, 2002)

3. J. van der Heijden, Building Regulatory Enforcement Regimes: Comparative Analysis of Private Sector Involvement in the Enforcement of Public Building Regulations (Delft University Press, Delft, 2009)

4. R. M. Dowsett, C. F. Harty, Construction Management and Economics 7, 1-16 (2018)

5. Y. Li, C. Liu, International Journal of Construction Management 4, 1-12 (2018)

6. S. D. Robert, K. A. Kirytopoulos, S. T Ponis, S. Gayialis, I. Tatsiopoulos, International Journal of Construction Management 4, 1-19 (2018)

7. A. Adeyemi, S. Venkatachalam, D. Root, Construction Management and Economics 2, 1-21 (2019)

8. H. Lingard, D. Oswald, T. Le, Construction Management and Economics 2, 1-17 (2019)

9. S. D. Smith, Construction Management and Economics 11, 1-5 (2018)

10. G. Nørkjaer, P. A. Gade, K. Otrel-Cass, K. Svidt, Construction Management and Economics 12, 1-15 (2018)

11. Government of the Russian Federation. Resolution of 07/21/2010 No. 468 "On the order of the construction control in the implementation of construction, reconstruction and overhaul of capital construction"

12. Town Planning Code of the Russian Federation (as amended on August 3, 2018) (revised from August 14, 2018) RF Code of December 29, 2004 N190-Ф3

13. Resolution No. 468 dated July 21, 2010 "On the order of the construction control in the implementation of construction, reconstruction and overhaul of capital construction"

14. Resolution of 01.02.2006, No. 54 "On State Construction Supervision in the Russian Federation"

15. Federal law of 12.27.2002, No. 184-FZ "On Technical Regulation"

16. Federal Law dated December 30, 2009, No. 384-Ф3 "Technical Regulations on the Safety of Buildings and Structures"

17. D. Topchiy, A. Tokarskiy, IOP Conference Series: Materials Science and Engineering (2018)

18. I. L. Abramov, A. A. Lapidus, Scientific Review 4, 6-9 (2017)

19. P. Oleinik, A. Yurgaytis, MATEC Web of Conferences 117, 00130 (2017)

20. D. Topchiy, A. Shatrova, A. Yurgaytis, MATEC Web of Conferences 193, 05032 (2018)

21. P. Oleinik, A. Yurgaytis, MATEC Web of Conferences 193, 05010 (2018) 